\title{
Synthesis and Crystal Structure of Pyrano-[3,2-c]-chromene Derivative
}

\author{
S. Naveen, ${ }^{*}$ Dinesh Manvar, ${ }^{* *}$ Alpesh Parecha, $* *$ Anamik Shah, $* *$ \\ Sridhar M. ANANDALWAR, ${ }^{* \dagger}$ J. Shashidhara PRASAD* \\ * Department of Studies in Physics, University of Mysore, Mysore 570 006, India \\ **Department of Chemistry, Saurashtra University, Rajkot 360 005, India
}

\begin{abstract}
The title compound was synthesized and the structure was investigated by X-ray crystallography. The compound crystallizes in the triclinic crystal class in the space group $P \overline{1}$ with cell parameters $a=7.794(5) \AA, b=11.736(1) \AA, c=$ 12.422(1) $\AA, \alpha=112.27(2)^{\circ}, \beta=97.383(5)^{\circ}, \gamma=103.876(5)^{\circ}, Z=2$. The structure exhibits intermolecular hydrogen bonds of the type $\mathrm{N}-\mathrm{H} \cdots \mathrm{O}$ and $\mathrm{N}-\mathrm{H} \cdots \mathrm{N}$.
\end{abstract}

(Received October 7, 2005; Accepted February 7, 2006; Published on web April 20, 2006)

4-Hydroxy coumarin serves as a powerful tool for constructing 3,4-positionally fused heterocyclic systems. ${ }^{1}$ The scaffolds, composed of three skeletal rings including coumarin and fused pyran skeleton, possess anti-bacterial, ${ }^{2}$ coronary dialatory, anticoagulant and anti-viral activity. Earlier our research group prepared many derivatives of the fused heterocycles at the C3-C4 position of coumarin to study their anti-HIV activity; the compounds exhibited good antimicrobial activity. This observation has further led us to work on synthetic aspects of the fused benzopyran system at the 3,4 positions. We present here the synthesis and structure of the title molecule. The molecule is being assessed for biological activity.

Preparation of (3-phenoxybenzyl)melanonitrile. In a clean dry beaker, 3-phenoxy benzaldehyde $(0.01 \mathrm{~mol})$ was taken and cooled to $5^{\circ}$; then, melanonitrile $(0.01 \mathrm{~mol})$ was added dropwise along with piperidine ( 3 to 4 drops) as a base catalyst. After thorough mixing and keeping at room temperature, the reaction mass was poured into ice cold water, filtered, washed with water, dried and recrystallised from methanol. The yield was $85-87 \%$.

Preparation of 2-amino-5-oxo-4-(3-phenoxyphenyl)-4H,5Hpyrano-[3,2-c]chromene-3carbonitrile. A mixture of 4hydroxycoumarin $(0.01 \mathrm{~mol})$ and melanonitrile $(0.01 \mathrm{~mol})$ in ethanol $(25 \mathrm{ml})$ and piperidine (6 to 7 drops as a base catalyst) was refluxed on a steam bath for 3 to $4 \mathrm{~h}$. The solvent was then removed by treating in a rotary evaporator, and the product was washed with chilled methanol and filtered. The solid product was crystallized from DMF. The yield was $25 \%$ with a melting

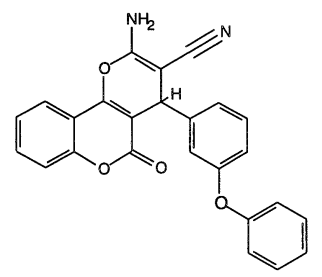

Fig. 1 Schematic diagram.

$\dagger$ To whom correspondence should be addressed.

E-mail: mas@physics.uni-mysore.ac.in point of $225^{\circ} \mathrm{C}$.

Method of crystallization. 2-Amino-5-oxo-4-(3phenoxyphenyl)-4H,5H-pyrano[3,2-c]chromene-3-carbonitrile $(0.5 \mathrm{~g})$ was taken in $10 \mathrm{ml}$ of DMF. One gram of charcoal was added and heated for 2 to $3 \mathrm{~min}$. The solution was filtered while hot through Whatmann 42 filter paper and corked using a filter paper. The solution was kept in a corked flask, which led to slow evaporation of the solvent. This gave good single crystals that were then washed with chilled ethanol. A schematic diagram of the molecule is shown in Fig. 1.

A single crystal of the title compound with dimensions of 0.3 $\times 0.3 \times 0.2 \mathrm{~mm}$ was chosen for X-ray diffraction studies. The data were collected on a DIPLabo Image Plate system with graphite monochromated Mo $K_{\alpha}$ radiation. Thirty six frames of data were collected in the oscillation mode with an oscillation range of $5^{\circ}$ and processed using Denzo. ${ }^{3}$ The reflections were merged with Scalepack. All of the frames could be indexed

Table 1 Crystal data and structure refinement table

\begin{tabular}{|c|c|}
\hline \multicolumn{2}{|l|}{ CCDC 294991} \\
\hline Empirical formula & $\mathrm{C}_{25} \mathrm{H}_{16} \mathrm{~N}_{2} \mathrm{O}_{4}$ \\
\hline Formula weight & 408.40 \\
\hline Temperature & $293(2) \mathrm{K}$ \\
\hline Wavelength & $0.71073 \AA$ \\
\hline Crystal system & Triclinic \\
\hline Space group & $P \overline{1} \quad Z=2$ \\
\hline $\begin{array}{l}\text { Cell dimensions } \\
\qquad \begin{aligned} a=7.794(5) \AA, b= \\
\alpha=112.27(2)^{\circ}, \beta\end{aligned}\end{array}$ & $\begin{array}{l}36(1) \AA, c=12.422(1) \AA \\
383(5)^{\circ}, \gamma=103.876(5)^{\circ}\end{array}$ \\
\hline Volume & $989.90(14) \AA^{3}$ \\
\hline$D_{\mathrm{c}}$ & $1.370 \mathrm{Mg} / \mathrm{m}^{3}$ \\
\hline$\theta_{\max }$ & $32.49^{\circ}$ \\
\hline$R$ & 0.0664 \\
\hline Data/restraints/parameters & $5807 / 0 / 281$ \\
\hline$(\Delta / \sigma)_{\max }$ & 0.000 \\
\hline$(\Delta \rho)_{\max }$ & $0.444 \mathrm{e}^{-3}$ \\
\hline$(\Delta \rho)_{\min }$ & $-0.283 \mathrm{e}^{-3}$ \\
\hline Refinement method & Full-matrix least-squares on $F^{2}$ \\
\hline Measurement & DIPLabo Kappa \\
\hline Program system & Denzo \\
\hline Structure determination & SHELXS-97 \\
\hline Refinement & full-matrix: SHELXL-97 \\
\hline
\end{tabular}




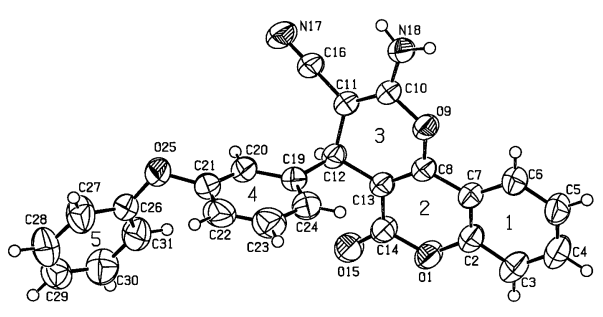

Fig. 2 ORTEP drawing of the molecule at $50 \%$ probability.

Table 2 Selected bond lengths $(\AA)$ and bond angles $\left({ }^{\circ}\right)$

\begin{tabular}{lrll}
\hline \multicolumn{1}{c}{ Atoms } & \multicolumn{1}{c}{ Length } & \multicolumn{1}{c}{ Atoms } & \multicolumn{1}{c}{ Length } \\
\hline O1-C2 & $1.381(2)$ & C10-N18 & $1.333(2)$ \\
O9-C10 & $1.3733(17)$ & O15-C14 & $1.208(2)$ \\
C8-C7 & $1.443(2)$ & C16-N17 & $1.145(2)$ \\
O9-C8 & $1.210(2)$ & O25-C21 & $1.395(2)$ \\
& & & \\
C11-C12-C19 & $110.35(13$ & N18-C10-O9 & $109.59(13)$ \\
C13-C12-C19 & $114.69(12)$ & C20-C19-C12 & $118.67(15)$ \\
O15-C14-O1 & $116.33(16)$ & C26-O25-C21 & $117.45(14)$ \\
N18-C10-C11 & $129.20(14)$ & C27-C26-O25 & $117.52(19)$ \\
\hline
\end{tabular}

using primitive triclinic lattice. The structure was solved by direct methods using SHELXS-97. ${ }^{4}$ The structure was refined by a full-matrix least squares method with anisotropic temperature factors for non-hydrogen atoms using SHELXL97. ${ }^{4}$ The hydrogen atoms were fixed at chemically acceptable positions and were refined with isotropic temperature factors. The crystal and experimental details are given in Table 1. An ORTEP drawing of the molecule at $50 \%$ probability is shown in Fig. 2. Table 2 gives selected bond lengths and bond angles of the non-hydrogen atoms.

The pyran ring [2] of the coumarin is planar, while the other pyran ring [3] adopts a flattened boat conformation with the atoms $\mathrm{O} 9$ and $\mathrm{C} 12$ deviating from the Cremer and Pople plane defined by atoms $(\mathrm{C} 8 \mathrm{C} 10 \mathrm{C} 11 \mathrm{C} 13)$ by $0.1213(16) \AA$ and
$0.1545(18) \AA$, respectively. The value of the puckering amplitude, ${ }^{5}$ (Q) is $0.2469(18) \AA$. The torsion angle about C13 $\mathrm{C} 12 \mathrm{C} 19 \mathrm{C} 24$ being $32.2^{\circ}$ reflects + syn-clinal confirmation of the phenyl ring [4] w.r.t the pyran ring [3]. The dihedral angle between the phenyl ring [4] and the fused benzopyran moiety(O1-C14) is $89.85(9)^{\circ}$, indicating that they are almost perpendicular to each other while that about the phenyl rings [4 $\& 5$ ] bridged by the oxygen is $71.93(13)^{\circ}$. The torsion angle about $\mathrm{C} 21 \mathrm{O} 25 \mathrm{C} 26 \mathrm{C} 31$ is $-52.3(3)^{\circ}$. The structure exhibits intermolecular hydrogen bonds of the type $\mathrm{N}-\mathrm{H} \cdots \mathrm{N}$ and $\mathrm{N}-\mathrm{H} \cdots \mathrm{O}$. The intermolecular hydorgen bonds are $\mathrm{N}(18)-\mathrm{H}(19 \mathrm{~A}) \cdots \mathrm{N}(17)$ (3.035(3) $\left.\mathrm{A}, \quad 163.1(3)^{\circ}\right), \quad \mathrm{N}(18)-\mathrm{H}(19 \mathrm{~B}) \cdots \mathrm{O}(15) \quad(2.913(2) \AA$, $\left.164.78(2)^{\circ}\right)$ with symmetry codes $(1-x, 1-y,-z)$ and $(-1+x$, $y, z)$, respectively. The packing of the molecules exhibit layered stacking when viewed down the $a$-axis. These layers are linked via hydrogen bonds, which in turn form a linear polymeric chain.

\section{Acknowledgements}

The authors are thankful to Department of Chemistry, Saurashtra University, Rajkot for providing a laboratory facility and DST, Government of India for financial assistance under project SP/I2/FOO/93.

\section{References}

1. M. Darbarwar and V. Sundermurthy, Synthesis, 1997, 337.

2. N. M. Dodia, and A Shah., Ind. J. Pharm. Sci., 2001, 63, 221.

3. Z. Otwinowski and W. Minor, Macromolecular Crystallography, 1997, 276: part A, 307-326, ed. C. M. Carter Jr. and R. M. Sweet, Academic Press, New York.

4. G. M. Sheldrick, SHELXS-97, SHELXL-97, 1997, University of Göttingen, Germany.

5. D. Cremer and J. A. Pople, J. Am. Chem. Soc., 1975, B12, 1354. 